\title{
Mass spectra and incident energy resolved spectra after collisions of hydrocarbon ions with fusion-plasma tungsten thin films
}

\author{
Bilal Rasul ${ }^{1 a}$, Hira Naz ${ }^{1 b}$ \\ RECEIVED ON 04.12.2018, ACCEPTED ON 03.05.2019
}

\begin{abstract}
We have performed surface-induced dissociation studies of small deuterated hydrocarbon cations i.e. $\mathbf{C D}_{\mathbf{x}}{ }^{+}$ with $x=2-4$, colliding with two types of tungsten-coated surfaces, in the incident energy range between $E_{\text {in }}=0$ $\mathrm{eV}$ approximately, up to $\mathrm{E}_{\text {in }}=100 \mathrm{eV}$. A $34 \mathrm{~nm}$ thick $\mathrm{W}$ layer deposited on stainless steel using the Thermionic Vacuum Arc (TVA) method and a small sample of a tile cut from ASDEX-Upgrade tiles, consisting of PlasmaSprayed (PS) tungsten on carbon, are exposed to ion flux in these experiments. A double-focussing reverse geometry BE mass spectrometer, is used under ultra high vacuum conditions. Mass spectra of secondary charged particles are recorded via time-of-flight mass analyser. For comparison, we have performed equivalent study on polished stainless steel under experimental status explained in Section 2 below. At very low energies i.e. below $10 \mathrm{eV}$, only surface reflected projectiles are seen, whereas most of them are neutralized by surface micro charges. We observed that the fragmentation pattern of the small molecular ions at a given energy is strongly dependent on the surface. The roughness of both of the said thin films and their reflectivity for the projectile ion beam is studied by analysis of the ion yields of the reaction products.
\end{abstract}

Keywords: Plasma-Material Interactions, Fusion Relevant Materials, Ion-Surface Collisions

\section{INTRODUCTION}

$\mathrm{I}$ on-surface collisions experiments have been a good source of yielding essential data for future fusion reactors. At the diverter and limiter regions of fusion devices, collisions of hypothermal plasma particles i.e. deuterium (D) or tritium (T) result physical processes like erosion. As a result, codeposition of species may occur along with other particles. Thus the interaction of molecular ions with fusion relevant materials e.g. tungsten (W), beryllium (Be) and/or Carbon Fibre Composite (CFC) has been recognized and appreciated.

Tungsten has been replaced with carbon in many devices owing to its lower sputter yield and low erosion under critical heat loads, therefore used at divertor in reactors like ASDEX and JET [1-4] and further proposed for ITER divertor [5]. Although tungsten has been studied the most of all fusion candidate materials, in last couple of years, but a complete knowledge of the effects of exposure to plasma constituents on tungsten has not yet been established [6,7].

Dissociation of small hydrocarbons $\mathrm{CH}_{\mathrm{n}}{ }^{+}$where $\mathrm{n}=1$, $2, \ldots$ and fluorocarbons $\mathrm{CF}_{\mathrm{n}}{ }^{+}$has been studied on aluminium surfaces for the study of surface processes [8]. Experiments of interacting $\mathrm{SF}_{4}{ }^{+}$and $\mathrm{SF}_{4}{ }^{2+}$ have been performed to investigate surface charge exchange and surface induced dissociations [9]. Recently, hydrocarbon covered W, Be and C surfaces

${ }^{1}$ Department of Physics, University of Sargodha, 40100 Sargodha, Pakistan.

Email: bilal.rasul@uos.edu.pk (Corresponding Author), bhiranazmaken@ gmail.com

This is an open access article published by Mehran University of Engineering and Technology, Jamshoro under CC BY 4.0 International License. 


\section{Mass spectra and incident energy resolved spectra after collisions of hydrocarbon ions with fusion-plasma tungsten thin films}

are exposed to Nitrogen based gas phase cations, proving that the heterogeneous reactions occur only with the surface adsorbates [10]. In particular, W has been investigated in many other aspects e.g. hydrogen saturation by low energy ion scattering [11], tritium retention by baking in hydrogen atmosphere [12] and deuterium permeation through $\mathrm{W}$ [13].

In this paper, a systematic comparison is made between tungsten thin films deposited by TVA and PS, with the help of analytical study of surface-induced reactions with an emphasis on surface-induced dissociations. $\mathrm{CD}_{2}{ }^{+}, \mathrm{CD}_{3}{ }^{+}$and $\mathrm{Ar}^{+}$ion beams are collided with a PS tungsten surface in the incident energy range from about $0 \mathrm{eV}$ to $100 \mathrm{eV}$. We also report results of the impact of $\mathrm{CD}_{2}{ }^{+}, \mathrm{CD}_{3}{ }^{+}$and $\mathrm{CD}_{4}{ }^{+}$ upon impact on tungsten film by TVA. Secondary ion mass spectra are recorded by time-of-flight mass spectrometer.

\section{EXPERIMENTAL DETAILS}

\subsection{Double focussing mass spectrometer}

Secondary ion mass spectra (SIMS) were taken with the help of tandem mass spectrometer apparatus (Bmagnetic sector, E-electric sector, S-surface, TOFtime-of-flight (BESTOF shown here in Fig. 1 (details in [14-16],). Relative abundance of the product ions as a function of incident ion energy, was also quantified, called ERMS energy resolved mass spectra. A Niertype electron impact source is used to ionize gas phase molecules at pressures of about $10^{-5}$ Torr, with $74 \mathrm{eV}$ electrons. Ions are extracted and accelerated to almost $3 \mathrm{keV}$ for mass and energy analysis. Focused by an Einzel lens and retarded to $\mathrm{E}_{\text {in }}$ i.e. incident energy, ions strike the target surface at an impact angle of $45^{\circ}$. Full width at half maximum FWHM of the projectile ions beam was $100 \mathrm{meV}$ while the ion currents were 100 pA for $\mathrm{CD}_{2}{ }^{+}$and around $200 \mathrm{pA}$ for $\mathrm{CD}_{3}{ }^{+}$and $\mathrm{CD}_{4}{ }^{+}$ focussed to a cross section of $2 \mathrm{~mm}^{2}$ (spot size calculated by ion beam simulations using SIMION). Secondary ions were analysed by time-of-flight MS; a flight tube of $80 \mathrm{~cm}$ in length. A double-stage multichannel plate analyzer with a time resolution of $8 \mathrm{~ns}$ per channel is used to collect these ions.

Keeping the shutter valve between the collision chamber and sector field mass spectrometer closed, base pressure in the collision chamber was about $10^{-9}$ Torr. This pressure could increase to a maximum one order of magnitude while opening the said beam-line valve. Under these pressure conditions, it is obvious that the surface remained covered with hydrocarbons.

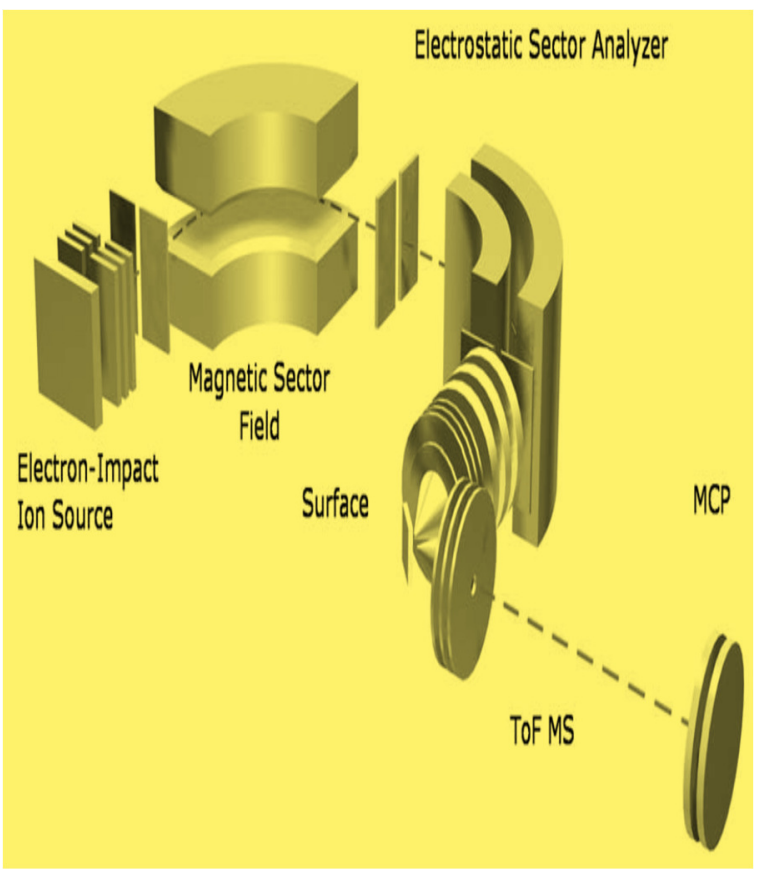

Fig. 1: SCHEME OF MASS SPECTROMETER BESTOF

\subsection{Tungsten film deposition}

The tungsten films of thickness $34 \mathrm{~nm}$, are deposited on stainless steel covered with residual-pressure hydrocarbons by TVA, that involves production of a high potential (300-2000 V) and low current $(0.1-2$ A) plasma, in the pure vapours of the tungsten metal to be deposited $[17,18]$. Important parameters include: cathode filament current; $150 \mathrm{~A}$, arc current; $2 \mathrm{~A}$, the arc voltage; $1000 \mathrm{~V}$ d.c. A smooth film (despite the presence of few droplets), with a roughness in the range of 20-30 nm, is seen using atomic force microscopy.

Another tungsten thin film deposited on carbon by PS is obtained ASDEX-Upgrade vacuum vessel. Highdensity plasma spray technique is used to coat tungsten on graphite whereas a layer of $10 \mu \mathrm{m}$ thick $\mathrm{Re}$ is applied between carbon and tungsten that prevents carbon diffusion leading to tungsten carbide formation. 


\section{Mass spectra and incident energy resolved spectra after collisions of hydrocarbon ions with fusion-plasma tungsten thin films}

\section{RESULTS AND DISCUSSION}

\subsection{Surface Induced Reaction (SIR) studies}

Regarding fusion related investigations for low-energy interactions i.e. below $200 \mathrm{eV}$, there exist only few experimental studies especially for the interactions of hydrocarbons. But in last few years, surface-induced reactions including dissociation, have been developed as a method to study the fragmentation processes [1921]. The available data is scarce for deuterated hydrocarbon species which is definitely much more relevant regarding fusion plasma. Therefore, we have extended our ion-surface interaction studies from those reported in [22] to fusion relevant tungsten films. Mass spectra of product ions resulting from the interactions of $\mathrm{CD}_{2}{ }^{+}, \mathrm{CD}_{3}{ }^{+}$and $\mathrm{Ar}^{+}$with PS tungsten surfaces and $\mathrm{CD}_{2}{ }^{+}, \mathrm{CD}_{3}{ }^{+}$and $\mathrm{CD}_{4}{ }^{+}$during the impact with TVA tungsten films are measured on the double focussing mass spectrometer BESTOF. Respectively, incident energy resolved mass are also calculated which are relative abundances of projectile ions and product ions in percentages i.e. $I_{r e l}=100\left({ }^{I_{i}} / \sum I_{i}\right)$.

At $\mathrm{E}_{\mathrm{in}}=0 \mathrm{eV}$ (an average incident kinetic energy), only the projectile ion i.e. $\mathrm{CD}_{2}{ }^{+} \mathrm{m} / \mathrm{z} 16$ can be seen (Fig.2) that results from two different processes induced at the surface. Elastically scattered ions are diverted towards the TOF by surface micro charges (or the electric fields in the interaction region close the surface) with full energy and in-elastically scattered ions that practically hit the surface. In the TOF mass spectrum, we are able to see this difference in few measurements and the peak of the primary ion can be seen easily divided in two peaks at the top, shown in Fig. 2 inset.

For an understanding of dissociation processes and comparative quantification of the respective product ions, mass spectra taken at $\mathrm{E}_{\mathrm{in}}=30 \mathrm{eV}$ taken after the collision of $\mathrm{CD}_{2}{ }^{+}$for the said tungsten surfaces are shown in figure. 3. SID products for $\mathrm{CD}_{2}{ }^{+} \mathrm{m} / \mathrm{z} 16 \mathrm{can}$ be seen during ion beam collisions with PS tungsten. Dissociation energetics yield that energy of about 4.65 $\mathrm{eV}$ is required in total, for $\mathrm{CD}_{2}{ }^{+} \rightarrow \mathrm{CD}^{+} \mathrm{m} / \mathrm{z} 14+\mathrm{D}$. We have calculated from our earlier experiments that a 6 $\%$ of translational kinetic energy is transformed into internal energy of projectile ions i.e. in this case, 1.8 $\mathrm{eV}$ is additionally added into internal energy for molecule to be dissociated.

As stated elsewhere [23-25], these fragmentations of the projectile ions occur after striking surfaces, in a uni-molecular way. A very high yield of the projectile ions signs perhaps the higher reflectivity of the smooth TVA tungsten film.

Surface induced reaction products are also seen which are observed behaving similarly for both thin films. These are the ions formed as projectile ions or their dissociated products react with surface adsorbed hydrocarbons:

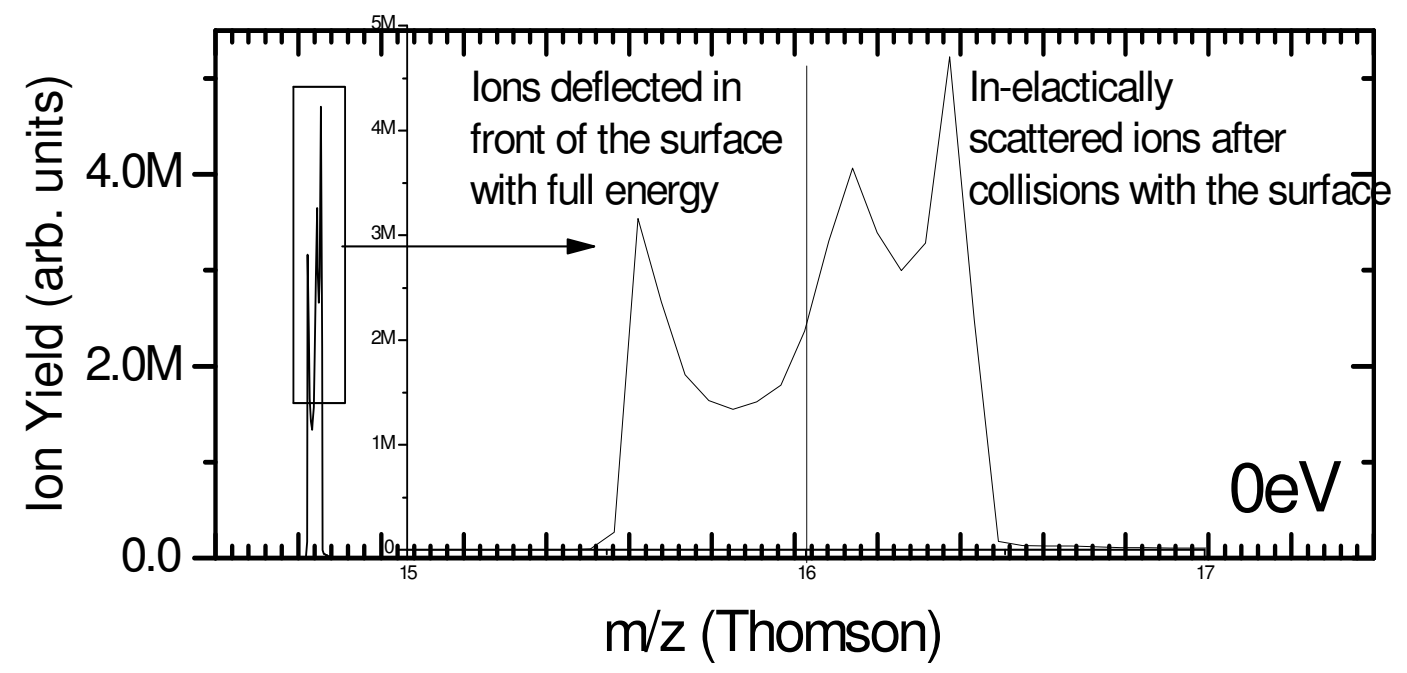

FIG. 2. SECONDARY ION MASS SPECTRUM (SIMS) OF $\mathrm{CD}_{2}{ }^{+}$COLLIDING WITH A PLASMA SPRAYED TUNGSTEN (PSW) SURFACE AT $E_{I N}=0$ EV.

Mehran University Research Journal of Engineering and Technology, Vol. 39, No. 3, July 2020 [p-ISSN: 0254-7821, e-ISSN: 2413-7219] 


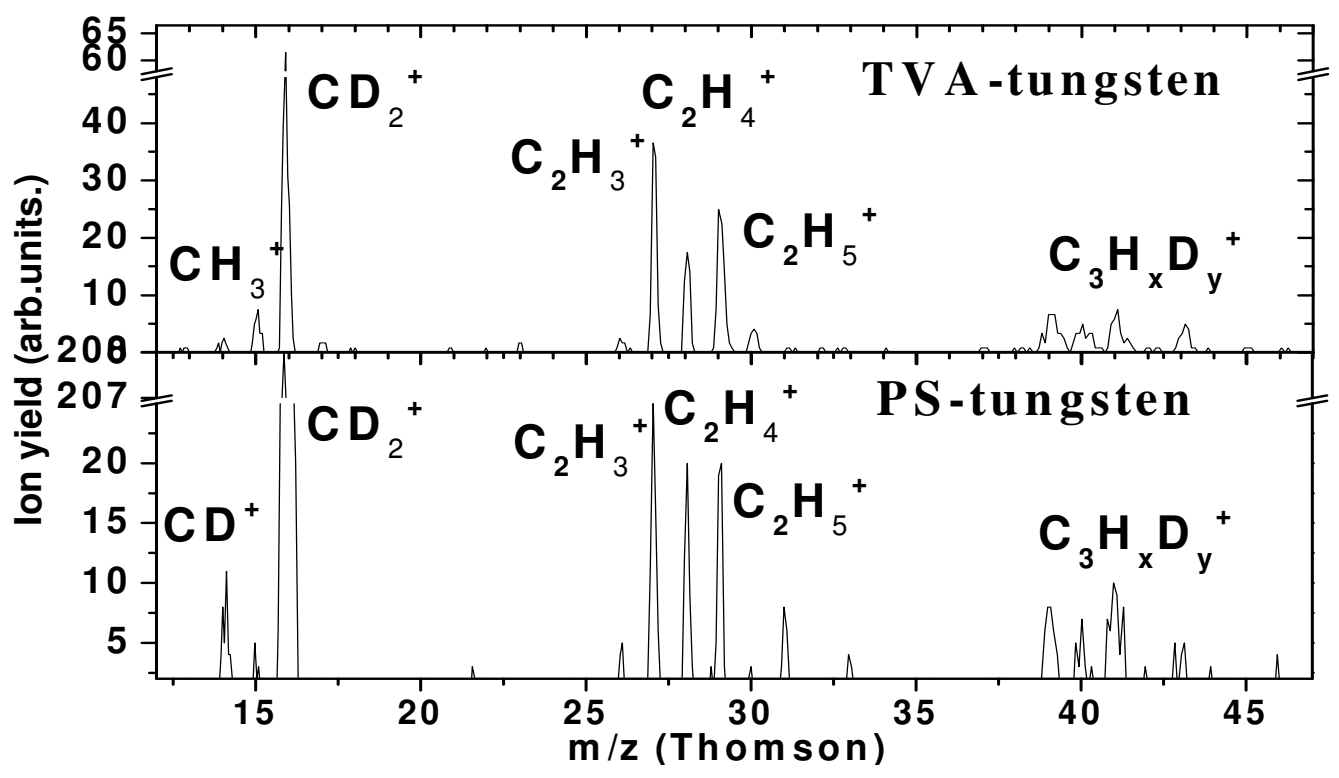

FIG. 3: PRODUCT ION MASS SPECTRA OF $\mathrm{CD}_{2}{ }^{+}$INTERACTING WITH INCIDENT ENERGY OF $30 \mathrm{EV}$, WITH HYDROCARBON COVERED PS TUNGSTEN AND TVA TUNGSTEN FILMS.

a) Hydrogen atom pickup reaction resulting the formation of $\mathrm{CD}_{2} \mathrm{H}^{+} \mathrm{m} / \mathrm{z} 17$ is seen barely for TVA tungsten surface.

$\mathrm{CD}_{2}{ }^{+}+\mathrm{H}-\mathrm{S} \rightarrow \mathrm{CD}_{2} \mathrm{H}^{+}(\mathrm{m} / \mathrm{z} 17)+-\mathrm{S}$

Further dissociation of this product results the formation of $\mathrm{CDH}^{+} \mathrm{m} / \mathrm{z} 15$ i.e.

$\mathrm{CD}_{2} \mathrm{H}^{+} \rightarrow \mathrm{CDH}^{+}(\mathrm{m} / \mathrm{z} 15)+\mathrm{D}+-\mathrm{S}$

b) The product ions with even $\mathrm{m} / \mathrm{z}$ i.e. $\mathrm{m} / \mathrm{z}=26,28$ and 30 of $\mathrm{C} 2$ group and $\mathrm{m} / \mathrm{z}=40$ and 42 of $\mathrm{C} 3$ group result by either

i- reactions that result $\mathrm{C}$-chains to build with e.g $\mathrm{CH}_{2}$ group of surface hydrocarbons e.g. $\mathrm{CD}_{2}{ }^{+}$

$+\mathrm{CH}_{2}-\mathrm{S} \rightarrow \mathrm{C}_{2} \mathrm{D}_{\mathrm{x}} \mathrm{H}_{\mathrm{y}}{ }^{+}+-\mathrm{S}$ or

ii- chemical reactions of projectile ions with its own SID products e.g.

$\mathrm{CD}_{2}{ }^{+}+\mathrm{CD}_{\mathrm{x}} \rightarrow \mathrm{C}_{2} \mathrm{D}_{\mathrm{x}}{ }^{+}+-\mathrm{S}$ and likewise for $\mathrm{C} 3$ group.

c) The reaction products of odd $\mathrm{m} / \mathrm{z}$ i.e. $\mathrm{m} / \mathrm{z}=27,29$ and 31 of $\mathrm{C} 2$ group of hydrocarbons and $\mathrm{m} / \mathrm{z}=39$, 41 and 43 of $\mathrm{C} 3$ group, are a combination of ipure surface-sputtered hydrocarbons e.g. $\mathrm{C}_{2} \mathrm{H}_{3}{ }^{+}$ $\mathrm{m} / \mathrm{z} 27$ and $\mathrm{C}_{3} \mathrm{H}_{3}{ }^{+} \mathrm{m} / \mathrm{z} 39$ and ii- C-chain build-up reaction products formed by reactions given in subsection (b).

\subsection{Ion yields}

Reflection properties of the surfaces in bulk or in the form of thin films can be studied by the quantitative analysis of the reflected projectile ions as well sputtered ions. Although the absolute ion yields of these ions, depend strongly upon experimental conditions like pressure in the collision chamber, potentials at the secondary lenses of the lens stack including pulsing lens, but here we present primary results about the nature of the surfaces under normalized conditions.

The respective ratios of the molecular ions appearing as a result of physical sputtering of the surface adsorbed hydrocarbon layers is shown in Table 1. It is clear that the ratio of the yield $\mathrm{m} / \mathrm{z} 27$ to that of $\mathrm{m} / \mathrm{z} 29$ increases in the whole measured energy range from 1.10 to 1.47 . Moreover, the ratio of the yield of $\mathrm{m} / \mathrm{z} 39$ to that of $\mathrm{m} / \mathrm{z} 41$ also increases from 0.55 to 0.90 but the ratio of the yield of $\mathrm{m} / \mathrm{z} 39$ to that of $\mathrm{m} / \mathrm{z} 43$ does not show a clear trend.

Total ion yields of all the secondary and deflected projectile ions is calculated, for an optimized ion current of $200 \mathrm{pA}$ and 10 hours exposure time at $\mathrm{E}_{\mathrm{in}}=$ $10 \mathrm{eV}$. Surface induced reactions are studied by four different projectile ions i.e. $\mathrm{CD}_{2}{ }^{+}, \mathrm{CD}_{3}{ }^{+}$and $\mathrm{CD}_{4}{ }^{+}$and $\mathrm{Ar}^{+}$on two different surfaces i.e. PS and TVA 


\section{Mass spectra and incident energy resolved spectra after collisions of hydrocarbon ions with fusion-plasma tungsten thin films}

tungsten. At an incident energy of $10 \mathrm{eV}$, we find that total ion yield of secondary ions is the highest for tungsten film deposited by thermionic vacuum arc method. Projectiles deflected in front of the surface contribute as major part of the ions that arrive the detector. Thus we propose a conclusion that these tungsten thin films made by TVA are much more reflective and smooth as compared to other investigated tungsten surfaces.

TABLE 1. RESPECTIVE RATIOS OF THE SECONDARY ION YIELDS AFTER COLLISION OF AR ${ }^{+}$ON PS-W.

\begin{tabular}{|c|c|c|c|}
\hline $\begin{array}{l}\text { Incident } \\
\text { energy of } \\
\text { the } \\
\text { projectile } \\
\text { ion beam } \\
\text { (eV) }\end{array}$ & $\begin{array}{l}\text { Ratio of } \\
\text { the yield } \\
\text { of } \mathrm{m} / \mathrm{z} 27 \\
\text { to the } \\
\text { yield of } \\
\mathrm{m} / \mathrm{z} 29\end{array}$ & $\begin{array}{l}\text { Ratio of } \\
\text { the yield } \\
\text { of } \mathrm{m} / \mathrm{z} 39 \\
\text { to the } \\
\text { yield of } \\
\mathrm{m} / \mathrm{z} 41\end{array}$ & $\begin{array}{l}\text { Ratio of } \\
\text { the yield } \\
\text { of } \mathrm{m} / \mathrm{z} 39 \\
\text { to the } \\
\text { yield of } \\
\mathrm{m} / \mathrm{z} 43\end{array}$ \\
\hline 30 & & 0.56 & 0.98 \\
\hline 50 & & 0.6 & 1.10 \\
\hline 100 & & 0.65 & 0.96 \\
\hline 150 & 1.47 & 0.90 & 1.33 \\
\hline
\end{tabular}

The total ion yield of all the product ions and projectile ions plotted against incident energy can be analyzed partially to study the nature of the phenomenon induced by the surface. In Fig.4 (upper graph), breakdown curves of the projectile ions $\left(\mathrm{CD}_{2}{ }^{+}, \mathrm{CD}_{3}{ }^{+}\right.$ and $\mathrm{Ar}^{+}$) after interaction with PS tungsten, are shown. Here the projectile ions are dissociated via surface induced excitation or neutralized via charge exchange with surface adsorbed hydrocarbons. Chemical reactions between projectile ions or its dissociated products with adsorbates, also contribute to total ion yields. Physical sputtering of surface adsorbates by energetic beam results into a sharp increase in the total ion yield. By analyzing the similar curves for TVA tungsten surfaces, in the light of above mentioned processes, physical sputtering of the surface adsorbed hydrocarbons does not seem to be very prominent phenomenon in the higher incident energy range measured. Comparative lesser sputtering yield from TVA tungsten surface signs the lesser content of adsorbed hydrocarbons and/or the smoothness of thermionic vacuum arc tungsten film as compared to plasma sprayed tungsten.

Fig. 5 shows the relative abundances of projectile ions plotted against incident energies, that are calculated after the impact of $\mathrm{CD}_{2}{ }^{+}$and $\mathrm{CD}_{3}{ }^{+}$with polished stainless steel surface, PS and TVA tungsten thin films, for energy up to $100 \mathrm{eV}$. The relative ion abundance of $\mathrm{CD}_{2}{ }^{+}$(Fig. 5 (a)) is always higher for

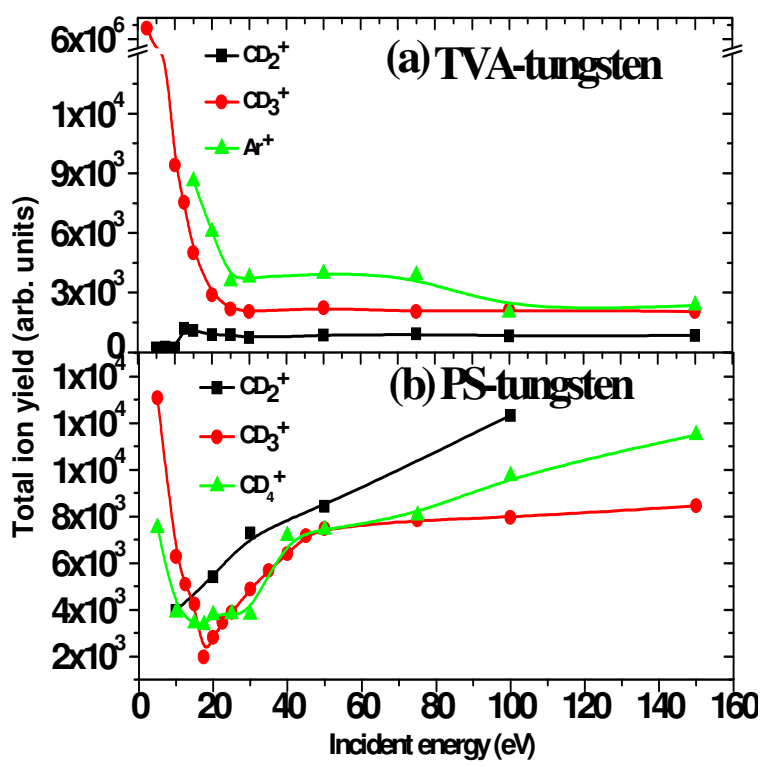

FIGURE 4: TOTAL ION YIELDS OF IONS AGAINST INCIDENT ENERGY FOR $\mathrm{CD}_{\mathrm{X}}{ }^{+} \mathrm{AND} \mathrm{AR}^{+}$AFTER IMPACT WITH TUNGSTEN THIN FILMS.

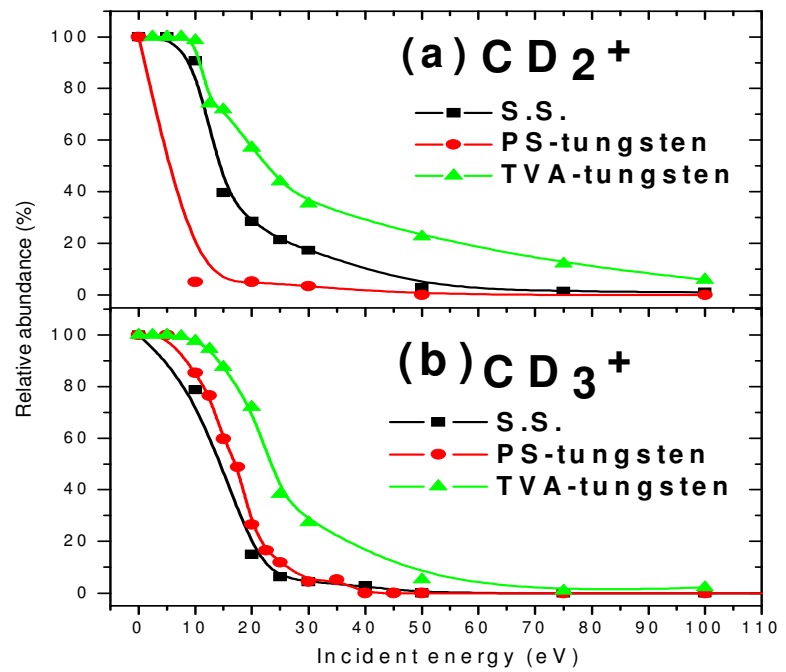

FIG.5: RELATIVE ION YIELDS OF PROJECTILE IONS AGAINST INCIDENT ENERGY FOR (A) $\mathrm{CD}_{2}{ }^{+} \mathrm{AND}$ (B) $\mathrm{CD}_{3}{ }^{+}$

TVA tungsten surface in comparison to other investigated surfaces (twice with respect to that with S.S. at $15 \mathrm{eV}$ to a maximum of about 20 times at 50 $\mathrm{eV})$. As translational energy may transform to internal energy of surface excited molecules, during interaction with surface resulting, surface induced dissociation processes, it is obvious from these results 


\section{Mass spectra and incident energy resolved spectra after collisions of hydrocarbon ions with fusion-plasma tungsten thin films}

that the TVA tungsten film contributes to a lesser extent in such transformation.

In Fig. 5 (b), relative abundance of $\mathrm{CD}_{3}{ }^{+}$ions is seen higher for TVA tungsten film, in the measured energy range with respect to that with other target materials indicating the smaller amount of energy transfer from kinetic to internal modes which ultimately increases the fragmentation threshold on the energy scale.

\section{CONCLUSIONS}

We have successfully studied surface induced dissociation properties and reflection properties of fusion relevant tungsten surfaces with the help of ionsurface collisions. Small hydrocarbon cations are interacted with two different thin films of tungsten made by thermionic vacuum arc and plasma spray methods deposited on stainless steel and carbon, respectively. The TVA tungsten thin films, in this preliminary study, seem to be much more reflective and even smoother on the micro level when compared to PS tungsten films.

\section{ACKNOWLEDGMENTS}

The first author is thankful to Paul Scheier, Institute of Ionphysics and Applied Physics, University of Innsbruck, Austria and C. P. Lungu, National Institute for Laser, Plasma and Radiation Physics, Bucharest, Romania, for their support in thin film deposition and collision experiments.

\section{REFERENCES:}

[1] Abernethy, R. G., "Predicting the performance of tungsten in a fusion environment: a literature review", Journal of Material Science and Technology, Vol. 33, No. 4, pp. 388, 2017.

[2] Bolt, H., Barabash, V., Federici, G., Linke, J., Loarte, A., Roth, J., and Sato, K., "Plasma facing and high heat flux materials - needs for ITER and beyond". Journal of Nuclear Materials, Vol. 307, No. 1, pp. 43, 2002.

[3] Davis, J., Barabash, V., Makhankov, A., Plöchl, L., and Slattery, K., "Assessment of tungsten for use in the ITER plasma facing components". Journal of Nuclear Materials, Vol. 258, No. 1, pp. 308. 1998.

[4] Romanelli, F., "Overview of the JET results with the ITER-like wall”. Nuclear Fusion, Vol. 53, No. 10, pp. 104002, 2013.

[5] Janeschitz, G., Borrass, K., Federici, G., Igitkhanov, Y., Kukushkin, A., Pacher, H. D., Pacher, G. W., and Sugihara, M., "The ITER divertor concept", Journal of Nuclear Materials, Vol. 220, pp. 73, 1995.

[6] Rieth, M., Dudarev, S. L., Gonzalez de Vicente S. M., Aktaa, J., Ahlgren, J., Antusch, S., Armstrong, D. E. J., Balden, M., Baluc, N., Barthe, M. F., Basuki, W. W., Battabyal, M., Becquart, C. S., Blagoeva, D., Boldyryeva, H., Brinkmann, J., Celino, M., Ciupinski, L., Correia, J. B., De Backer, A., Domain, C., Gaganidze, E., García-Rosales, C., Gibson, J., Gilbert, M. R., Giusepponi, S., Gludovatz, B., Greuner, H., Heinola, K., Höschen, T., Hoffmann, A., Holstein, N., Koch, F., Krauss, W., Li, H., Lindig, S., Linke, J., Linsmeier, C., López-Ruiz, P., Maier, H., Matejicek, J., Mishra, T. P., Muhammed, M., Muñoz, A., Muzyk,M., Nordlund, K., Nguyen-Manh, D., Opschoor, J., Ordás, N., Palacios, T., Pintsuk, G., Pippan, R., Reiser, J., Riesch, J., Roberts, S. G., Romaner, L., Rosiński, L., Sanchez, M., Schulmeyer, W., Traxler, H., Ureña, A., van der Laan, J. G., Veleva, L., Wahlberg, S., Walter, M., Weber, T., Weitkamp, T., Wurster, S., Yar, M. A., You, J. H., and Zivelonghi, A., "Recent progress in research on tungsten materials for nuclear fusion applications in Europe". Journal of Nuclear Materials, Vol. 432, No. 1-3, pp. 482-500, 2013.

[7] Federici, G., Andrew, P., Barabashi, P., Brooks, J., Doerner. R., Geier. A., Herrmann. A., Janeschetz. G., Kriger. K., Kukushkin. K., Loarte. A., Neu. R., Saibene. G., Shimada. M., Strohmayer. G., Sugihara., M., "Key ITER plasma edge and plasma-material interaction issues", Journal of Nuclear Materials, Vol. 313, pp. 11, 2003.

[8] Sugai, H., Mitsuoka, Y., Toyoda, H., “Observation of surface dissociation of low-energy polyatomic ions relevant to plasma processing", Journal of Vacuum Science and Technology A, Vol. 16, No. 1, pp. 290, 1998. 


\section{Mass spectra and incident energy resolved spectra after collisions of hydrocarbon ions with}

fusion-plasma tungsten thin films

[9] Feketeova, L., Grill, V., Zappa, F., Endstrasser, N., Rasul, B., Hermann, Z., Scheier, P., Märk, T.D., "Charge exchange, surface-induced dissociation and reactions of doubly charged molecular ions $\mathrm{SF}_{4}{ }^{2+}$ upon impact on a stainless steel surface. A comparison with surface-induced dissociation of singly charged $\mathrm{SF}_{4}{ }^{+}$molecular ions", International Journal of Mass Spectrometry, Vol. 276, No. 1, pp. 37, 2008.

[10] Herman, Z., Harnisch, M., Ballauf, L., Scheier, P., "Heterogeneous Reactions between nitrogen ions and hydrocarbons attached to solid surfaces", Chemické Listy, Vol. 112, No. 10, pp. 701, 2018.

[11] Piazza, Z. A., Ajmalghan, M., Ferro, Y., Kolasinski, R. D., " Saturation of Tungsten surface with hydrogen: A density functional theory study complemented by low energy ion scattering and direct recoil spectroscopy date", Acta Materilia, Vol. 145, pp. 388, 2018.

[12] Ahlgren, T., Jalkanen, P., Mizohata, K., Tuboltsev, V., Räisänen, J., Heinola K. and Tikkanen, P. "Hydrogen isotope exchange in tungsten during annealing in hydrogen atmosphere", Nuclear Fusion, Vol. 59, No. 2, pp. 026016, 2019

[13] Kapser, S., Balden, M., Silva, T. F., Elgeti, S., Manhard, A., Schmid, K., Selinger, T, $\mathrm{S}$, and Toussaint, Udo. "Influence of sub-surface damage evolution on low-energy-plasma-driven deuterium permeation through tungsten", Nuclear Fusion, Vol. 58, No. 5, pp. 56-27, 2018

[14] Mair, C., Fiegle, T., Biasioli, F., Wörgötter, R., Grill, V., Lezius, M., Märk, T.D., "Surfaceinduced reactions of polyatomic ions and cluster ions". Plasma Sources, Science and Technology, Vol. 8, No. 2, pp. 191, 1999.

[15] Qayyum, A., Ph.D Thesis, University of Innsbruck, Austria, 2002.

[16] Tepnual, T., Ph.D. Thesis, University of Innsbruck, Austria, 2005.

[17] Lungu, C. P., Mustata, I., Musa, G., Lungu, A.M., Zaroschi, V., Iwasaki, A., Tanaka, R., Matsumura, Y., Iwanaga, I., Tanaka, H., Oi, T., Fujita, K., „Formation of nanostructured Re-Cr$\mathrm{Ni}$ diffusion barrier coatings on $\mathrm{Nb}$ superalloys by TVA". Surface Coatings Technology, Vol. 200, No. 1-4, pp. 399, 2005.
[18] Lungu, C.P., Mustata, I., Zaroshci, V., Lungu, A.M., Anghel, A., Chiru, P., Rubel, M., Coad, P., Mathews, G.F., "Beryllium coatings on metals for marker tiles at JET: development of process and characterization of layers". Physica Scripta, Vol. 2007, No. T128, pp. 157, 2007.

[19] Cooks, R. G., Ast, T., Pradeep, T. "Reactions of ions with organic surfaces". Accounts of Chemical Research, Vol. 27, No. 11, pp. 316, 1994.

[20] Yeretzian, C., Beck, R. D., Whetten, R. L., "Cluster-Surface scattering in a reflectron collider: probing fullerenes by surface impact". International Journal of Mass Spectrometry and Ion Processes, Vol. 135, No. 2-3, pp. 79, 1994.

[21] Wu, Q., Hanley, L., "Reactive scattering, sputtering and dissociation of $32 \mathrm{eV}$ pyridine colliding with clean and pyridine covered silver", Journal of Physical Chemistry, Vol. 97, No. 11, pp. 2677, 1993.

[22] Qayyum, A., Schustereder, W., Mair, C., Tepnual, T., Scheier, P., Märk, T.D., "Ion surface collisions of $\mathrm{CH}_{3}^{+}, \mathrm{CH}_{4}^{+}, \mathrm{CH}_{5}{ }^{+}$and $\mathrm{CD}_{4}{ }^{+}$, Radiation Physics and Chemistry, Vol. 68, No. 1-2, pp. 257, 2003.

[23] Niehus, H., Heiland, W., Taglauer, H., "Lowenergy ion scattering at surfaces". Surface Science Reports, Vol. 17, No. 4-5, pp. 213, 1993.

[24] Kubišta, J., Dolejšek, Z., Herman, Z., "Energy partitioning in collisions of slow polyatomic ions with surfaces: ethanol molecular ions on stainless steel surfaces", European Journal of Mass Spectrometry, Vol. 4, No. 5, pp. 311, 1998.

[25] Roithová, J., Žabka, J., Dolejšek, Z., Hermann, Z., "Collisions of Slow Polyatomic Ions with Surfaces: Dissociation and Chemical Reactions of $\mathrm{CD}_{5}{ }^{+}, \mathrm{CD}_{4}{ }^{+\bullet}, \mathrm{CD}_{3}{ }^{+}$and Their Isotopic Variants on Room-Temperature and Heated Carbon Surfaces", Journal of Physical Chemistry B, Vol. 106, No. 33, pp. 8293, 2002. 